\title{
Distal attachments on a colonoscope: not all the same?
}

\section{(ㄷ) (1) $(2) \div$}

\author{
Authors \\ Sreedhari Thayalasekaran, Pradeep Bhandari
}

Institution

Queen Alexandra Hospital, Portsmouth, United Kingdom of Great Britain and Northern Ireland

Bibliography

DOI https://doi.org/10.1055/a-0996-8298 |

Endoscopy International Open 2019; 07: E1592-E1594

(c) Georg Thieme Verlag KG Stuttgart · New York

eISSN 2196-9736
Corresponding author

Professor Pradeep Bhandari, Queen Alexandra Hospital Gastroenterology, Southwick Hill Road Cosham Portsmouth PO6 3LY, United Kingdom of Great Britain and Northern Ireland

Fax: +023-9228-6000

deep3570@yahoo.co.uk
The reduction in interval colorectal cancer associated with an increase in the endoscopist's adenoma detection rate (ADR) is well established [1]. ADR is now widely accepted as a key performance indicator in colonoscopy quality assurance [2]. However, adenoma miss rates are reported to be as high as $20 \%$ [3].

Detection of adenoma during colonoscopy can be challenging because adenoma can be located behind flexures, haustral folds and, tight angulations. Evidence is conflicting on distal attachment devices that have recently emerged and which reportedly are associated with an increase in ADR. There are currently three types of distal attachment devices on the market; the transparent cap (Olympus, Tokyo); EndoCuff (Arc Medical, Leeds); and EndoRings (EndoAid, Israel).

The transparent cap was the first distal attachment device studied for which reports indicated increased polyp detection. It improves mucosal visualization by straightening colonic haustra, keeping the colonic lumen open with minimal air insufflation [4]. Because the cap projects $4 \mathrm{~mm}$ beyond the distal end of the colonoscope, it is associated with a learning curve.

The EndoCuff consists of soft projections that remain flat during colonoscopy insertion and open on withdrawal to enhance mucosal inspection behind colonic folds. Unlike the cap, the EndoCuff fits entirely over the colonoscope, without projecting beyond the distal end of the colonoscope, so it is much easier to use. There is no reduction in peripheral field of view [5].

The EndoRings device is flexible silicone and consists of two layers of large, soft circular rings that evert mucosal folds on withdrawal and allow adequate mucosal inspection. It is designed to keep the colonoscope tip away from the bowel wall, promoting all around colonic views [5] It is very good at flattening colonic folds and avoiding rapid withdrawal. However, it can be challenging to introduce the EndoRings device through a narrow, angulated sigmoid colon with diverticulosis.
In this edition of Endoscopy International Open, Marsano et al present a single-center parallel design trial in which 126 subjects were randomized to either standard colonoscopy (SC), cap-assisted colonoscopy (CAC) or EndoCuff-assisted colonoscopy (EAC). Colonoscopy was performed by three experienced endoscopists in an academic unit. Study participants were blinded to the intervention arm, but not the endoscopist. The primary outcome of the study was ADR. The study did not report a statistically significant difference in ADR for SC (52.4\%) versus CAC (40.5\%) versus EAC (54.8\%) $(P=0.37)$. This pattern of no statistically significant difference between treatment arms was also seen for the remaining study outcomes; proximal $A D R$, distal ADR, and sessile serrated adenoma detection rate. There was no difference in mean adenoma size between the groups, which is probably related to the diminutive mean adenoma size in all groups. The average withdrawal time was also similar in the SC, CAC and EAC groups (12.9 vs 12.4 and 13.0 minutes respectively, $P=0.86$. In this study, the pre-study ADR of each endoscopist was very high, with a range from $43 \%$ to $55 \%$. This study further supports the growing body of evidence that device-assisted colonoscopy has no additional benefit for endoscopists with a preexisting high ADR.

The authors should be congratulated for performing a trial comparing two distal devices against standard colonoscopy, but the small sample size is a major limitation and makes it difficult to draw definitive conclusions. The baseline ADR of the endoscopists was underestimated and the potential benefit was overestimated, resulting in the calculation of an incorrect sample size.

The current literature on efficacy of distal attachment devices is conflicting, with the majority of studies performed in tertiary academic units with their widespread use still to occur.

The impact of the transparent cap on PDR \pm ADR appears divided, with some studies showing an improvement $[6,7]$ and 
others no benefit $[8,9]$. A recent meta-analysis showed an improvement in PDR with use of the cap [10]. The recent meta-analysis by Desai et al also found an improvement in proximal adenoma detection with use of the cap [11]. A large multicenter study performed by endoscopists with a high baseline ADR ( $\geq 20 \%$ ) found no significant difference in ADR (28\%) between the two study arms [8]. In a large retrospective study where trainees performed the majority of colonoscopies, use of CAC showed a statistically significant increase in polyp and adenoma detection, compared to SC [7].

The transparent cap has been available longer than other distal attachment devices. It is difficult to make sense of the literature in the current era of higher-definition colonoscopes. Furthermore, most of the studies were performed at a time when there was less of emphasis on colonoscopy technique.

Initial data on the efficacy of EndoCuff in improving adenoma detection showed a benefit [12], but the subsequent evidence is inconsistent, with two large RCTs showing no additional benefit $[13,14]$. Interestingly, the two studies with a negative outcome were performed by endoscopists with a high baseline $A D R$, mirroring the findings by Marsano et al. A large multicenter RCT showed a marginal (4.7\%) increase in ADR with use of the EndoCuff compared to standard colonoscopy [15].

$A$ recent meta-analysis showed in improvement in ADR with $E A C$, with the greatest improvement observed when used by endoscopists with low to moderate ADRs [16].

EndoRings Is the newest distal attachment device and while an initial study showed a significant reduction in the adenoma miss rate with the device (10.4\%) versus SC (48.3\%) [17], a recent large multicenter study has shown no benefit in ADR [18]. More data on the EndoRings are required before we understand its role in neoplasia detection.

Finally, a recent multicenter trial by Rex et al showed that the EndoCuff increased adenoma detection more than EndoRings and standard colonoscopy [19]. The proposed mechanism of action of the distal attachment devices is to improve mucosal visualization by flattening colonic folds. It is difficult to understand how the EndoCuff device with shorter, softer prongs can flatten colonic folds and detect more adenomas compared to the EndoRings, with its wider rings. It is also noteworthy that this effect was not seen in all involved centers [19].

Data on distal attachment devices are appealing as they are safe, easy to use, and relatively inexpensive. However, the existing literature is flawed. Studies have not been adequately powered to draw definitive conclusions on differences between population groups and endoscopists with varying levels of experience. The majority of data also comes from tertiary centers in trial settings, where enthusiasm for or against their use can introduce investigator bias. The populations studied are heterogenous, with several studies performed on screening subjects with the greatest risk of adenoma. The current data show a trend towards endoscopists with low to moderate ADRs gaining the most benefit. Endoscopists with a high baseline ADR might benefit less as they have good scope handling with excellent tip control, which allows detailed inspection of the colonic mucosa behind folds, without slipping backwards.
We feel the distal attachments may show promise in increasing adenoma detection, but further studies are needed to make definitive conclusions about which endoscopist and which population group would benefit the most. The focus should still remain on improving basic colonoscopy techniques and performing simple measures well, such as scope handling, position change, and minimal time on withdrawal.

\section{Competing interests}

Dr. Bhandari has received educational grants from Olympus, Fujinon, Pentax, Norgine, and EndoAid Ltd that are unrelated to the content of this editorial.

\section{References}

[1] Corley DA, Jensen CD, Marks AR et al. Adenoma detection rate and risk of colorectal cancer and death. N Engl J Med 2014; 370: 1298 1306

[2] Kaminski MF, Thomas-Gibson S, Bugajski M et al. Performance measures for lower gastrointestinal endoscopy: a European Society of Gastrointestinal Endoscopy (ESGE) quality improvement initiative. United European Gastroenterol J 2017; 5: 309-334

[3] Rex DK, Cutler CS, Lemmel GT et al. Colonoscopic miss rates of adenomas determined by back-to-back colonoscopies. Gastroenterology 1997; 112: $24-28$

[4] Sumiyama KRE. Endoscopic Caps. Techniques in Gastrointestinal Endoscopy 2006; 8: 28-32

[5] Sreedhari TAA, Lazaros V, Subramaniam S et al. To cap/cuff or ring: do distal attachment devices improve the adenoma detection? Expert Rev Gastroenterol Hepatol 2019; 13: 119-127

[6] Rastogi A, Bansal A, Rao DS et al. Higher adenoma detection rates with cap-assisted colonoscopy: a randomised controlled trial. Gut 2012; 61: $402-408$

[7] Kim DJ, Kim HW, Park SB et al. Efficacy of cap-assisted colonoscopy according to lesion location and endoscopist training level. World J Gastroenterol 2015; 21: 6261-6270

[8] de Wijkerslooth TR, Stoop EM, Bossuyt PM et al. Adenoma detection with cap-assisted colonoscopy versus regular colonoscopy: a randomised controlled trial. Gut 2012; 61: 1426-1434

[9] Pohl H, Bensen SP, Toor A et al. Cap-assisted colonoscopy and detection of Adenomatous Polyps (CAP) study: a randomized trial. Endoscopy 2015; 47: $891-897$

[10] Ng SC, Tsoi KK, Hirai HW et al. The efficacy of cap-assisted colonoscopy in polyp detection and cecal intubation: a meta-analysis of randomized controlled trials. Am J Gastroenterol 2012; 107: 1165-1173

[11] Desai M, Sanchez-Yague A, Choudhary A et al. Impact of cap-assisted colonoscopy on detection of proximal colon adenomas: systematic review and meta-analysis. Gastrointest Endosc 2017; 86: 274-281 e3

[12] Floer M, Biecker E, Fitzlaff R et al. Higher adenoma detection rates with endocuff-assisted colonoscopy - a randomized controlled multicenter trial. PLoS One 2014; 9: e114267

[13] Bhattacharyya R, Chedgy F, Kandiah K et al. Endocuff-assisted vs. standard colonoscopy in the fecal occult blood test-based UK Bowel Cancer Screening Programme (E-cap study): a randomized trial. Endoscopy 2017; 49: 1043-1050

[14] van Doorn SC, van der Vlugt M, Depla A et al. Adenoma detection with Endocuff colonoscopy versus conventional colonoscopy: a multicentre randomised controlled trial. Gut 2017; 66: 438-445 
[15] Ngu WS, Bevan R, Tsiamoulos ZP et al. Improved adenoma detection with Endocuff Vision: the ADENOMA randomised controlled trial. Gut 2019; 68: $280-288$

[16] Williet N, Tournier Q, Vernet C et al. Effect of Endocuff-assisted colonoscopy on adenoma detection rate: meta-analysis of randomized controlled trials. Endoscopy 2018; 50: 846-860

[17] Dik VK, Gralnek IM, Segol O et al. Multicenter, randomized, tandem evaluation of EndoRings colonoscopy-results of the CLEVER study. Endoscopy 2015; 47: 1151-1158
[18] Hassan C, Senore C, Manes G et al. Diagnostic yield and miss rate of EndoRings in an organized colorectal cancer screening program: the SMART (Study Methodology for ADR-Related Technology) Trial. Gastrointest Endosc 2018: doi:10.1016/j.gie.2018.10.019

[19] Rex DK, Repici A, Gross SA et al. High-definition colonoscopy versus Endocuff versus EndoRings versus full-spectrum endoscopy for adenoma detection at colonoscopy: a multicenter randomized trial. Gastrointest Endosc 2018; 88: 335 - 344 